\title{
BELEZA, CONSTRUÇÃO DO SELF E REFLEXIVIDADE ENTRE AS MULHERES
}

\section{Veridiana Parahyba Campos ${ }^{1}$}

\begin{abstract}
Resumo
A relação direta entre beleza e mulheres ébastante naturalizada na nossa sociedade. Utilizando o pensamento sociológico para transformar essa naturalização numa questão sociológica, chegamos ao problema agencia-estrutura. A maioria das teorias sobre a relação entre mulheres e beleza aponta ou para o poder da estrutura (na forma de padrões estéticos hegemônicos), ou para o poder da agência individual. Nesse artigo, a partir do conceito de reflexividade, pretendo examinar como funciona a agencia das mulheres diante da centralidade da beleza e em que medida a estrutura influencia na construção de seus selves.
\end{abstract}

Palavras-chave: Beleza. Self. Reflexividade. Agência. Mulheres.

\section{BEAUTY, CONSTRUCTION OF THE SELF AND REFLEXIVITY AMONG WOMEN}

\begin{abstract}
The direct relationship between beauty and women is very naturalized in our society. Using sociological thought to transform this naturalization into a sociological question, we run into the structure-agency problem. The majority of theories about the relationship of women and beauty point either to the power of structure (in the form of hegemonic aesthetic patterns) or to the power of individual agency. In this article, based on the idea of reflexivity, I examine how women's agency works in

${ }^{1}$ Mestranda pelo Programa de Pós-Graduação em Sociologia da Universidade Federal de Pernambuco. End. eletrônico: emailveri@yahoo.com.br
\end{abstract}


relation to this centrality of beauty and how the influence of structure acts in the construction of their selves.

Keywords: Beauty. Self. Reflexivity. Agency. Women.

\section{O PROBLEMA}

U

$\mathrm{m}$ dos problemas centrais da Sociologia refere-se à discussão sobre a relação entre agência e estrutura. Várias teorias foram desenvolvidas na tentativa de resolver este problema, algumas delas embasadas na atribuição de muito poder à estrutura, outras na atribuição de muito poder à agência. Esta variação desmedida na imputação de poder é reflexo da diversidade de tentativas empreendidas para a compreensão de como, e através de que, se constitui a pessoa humana. Margaret Archer (2000, p. 51) resume o problema a "como conceituar 0 agente humano como alguém que é parcialmente formado por sua socialidade, mas que também tem a capacidade de transformar parcialmente sua sociedade".

Segundo a autora, a teoria social tem oscilado entre dois extremos. 0 pensamento Iluminista construiu e legitimou uma noção de ser humano subsocializado, chamado por ela de "homem da modernidade", o qual exerceria plenamente sua autonomia. Já a ascensão do pós-modernismo construiu uma imagem invertida deste sujeito (chegando mesmo a declarar sua morte) erigindo um indivíduo super-socializado, chamado por ela de "ser da sociedade". Especificamente no campo da Sociologia, a relação entre indivíduo e sociedade vem sendo pensada desde a institucionalização da mesma como prática científica legítima. Dentre os clássicos, Émile Durkheim chamou-nos a atenção para a autonomia da estrutura em relação ao agente. Já Weber focou seus esforços na compreensão do sentido que os agentes atribuíam às suas ações. Na tentativa de resolver qual das instâncias do mundo social exerce mais ativamente um poder autônomo, muitos teóricos de síntese migraram da questão indivíduo/sociedade para o problema agência/estrutura, tentando mostrar que, tanto o indivíduo quanto a sociedade exercem energias simultâneas e contínuas, que mutuamente se influenciam. Pierre Bourdieu, Anthony Giddens, Jürgen Habermas, dentre outros, empreenderam seus esforços nestas tentativas, alguns logrando mais êxito em determinados pontos.

0 presente artigo enquadra-se na esteira da discussão sociológica sobre a relação entre agência e estrutura. Contudo, nossas atenções se voltam especialmente para as mulheres, por entendermos que a agência delas vem sendo 
de alguma forma invisibilizada nas teorias sociológicas. Partindo do pressuposto de que a "beleza" é um valor central na construção de uma "identidade de mulher" hegemônica, e que nessa hegemonia encontramos as bases estruturais deste valor, problematizaremos aqui como, por meio da reflexividade, a agência feminina processa essa influência da estrutura de maneira ativa. Articulando algumas relações entre "beleza", construção do self e reflexividade, intentamos enfatizar a dimensão da agência feminina no processamento de valores tradicionalmente associados à femininidade 2 . No caso das teorias que tratam especificamente da questão dos padrões estéticos na vida das mulheres, normalmente há ou "sub" ou "super" estima dessa dimensão, o que nos parece questionável do ponto de vista sociológico.

Vale frisar que este artigo intenta fomentar uma discussão teórica acerca da capacidade de agência feminina, e, portanto, marcadores sociais de diferenciação, como, por exemplo, idade ou etnia, não serão especialmente levados em consideração. Nossa categoria de análise resumir-se-á apenas à categoria "mulheres". Todavia, para a construção de dados consistentes sobre o mundo empírico, é necessário um estudo que extrapole a dimensão teórica dessa discussão agência/estrutura e que seja recortado por categorias como classe, geração, etnia, etc. Possivelmente, cada um desses recortes analíticos sobrepostos nos levará a visualização de uma realidade específica, a qual, mediante análise, tornará ainda mais rica a discussão teórica. os "parâmetros" estruturais de beleza para mulheres jovens, idosas, ricas, pobres, donas de casa, profissionais, brancas, negras, sulistas ou nordestinas variarão tanto de acordo com esses próprios marcadores, quanto de acordo com o contexto em que tais mulheres estiverem inseridas. 0 que pretendemos neste artigo é fazer um exercício de abstração, ou seja, de construção de uma categoria analítica específica, que nos permitirá erigir uma ponte entre teoria e realidade social. Essa possibilidade de abstração está em acordo com a definição de Mauricio Domingues:

Ao dizer que estamos abstraindo alguma coisa, estarei me referindo à separação de um elemento... da vida social do contexto mais amplo em que se acha inserido... artificialmente, por razões metodológicas, que nos ajudam a analisar e compreender o sistema social, separar a parte do todo, o qual concretamente se caracteriza por ter seus diversos elementos imbricados, mais ou menos estritamente, uns com os outros (DOMINGUES, 2004, p. 10).

\footnotetext{
2 "Femininidade" significa puramente aquilo que diz respeito às mulheres; substitui "feminilidade", uma vez que esta última expressão está carregada de conteúdo normativo hegemônico acerca do "ser mulher", sendo comumente associada à doçura, delicadeza e sensibilidade.
} 
Num primeiro momento, mostraremos alguns fatos e números que revelam que em nossa sociedade a "beleza" representa um valor central na construção da identidade feminina. Em seguida, apresentaremos um breve panorama de algumas teorias acerca da questão corporal feminina e, at last, but not least, abordaremos a questão da reflexividade e sua importância para a construção do self.

\section{A Beleza COMO VALOR CENTRAL}

Partimos da constatação de que, ao longo dos últimos séculos, a preocupação com a estética corporal (a beleza) vem sendo atribuída às mulheres e que, por isso mesmo, na lógica do senso comum (lugar onde se difundem mais livremente todos os mitos sociais) apresentar elevada preocupação com a aparência é claramente "coisa de mulher". 0 resultado objetivo dessa atribuição historicamente acumulada é que, contemporaneamente, os cuidados com a aparência são de fato uma preocupação eminentemente feminina e, neste sentido, em grande medida, é por meio de sua agência que esse "mito" continua a ser reproduzido. Assim, este processo é simultaneamente externo a elas, na forma das expectativas sociais criadas em torno da própria definição do que é ser mulher, como também interno, na forma de uma demanda íntima emanada pelos selves particulares (em acordo ou não com as tais expectativas sociais).

Através de uma incursão a qualquer banca de revistas, podemos facilmente encontrar indícios desta centralidade do cuidado com a aparência física na vida das mulheres. Segundo Maria Célia Furtado, diretora-executiva da Associação Nacional dos Editores de Revistas (ANER), a vendagem de publicações voltadas para o público feminino ${ }^{3}$ que trazem em suas matérias de capa "fórmulas" para 0 incremento da beleza física só fica atrás das revistas semanais de variedades, sendo a revista Cláudia líder no segmento, com 403 mil exemplares por edição4. Vale frisar que praticamente todas estas revistas funcionam sob o comando de editoras-chefes mulheres, as quais dirigem suas revistas guiadas por pesquisas de mercado e de opinião. Se levarmos em conta que tais revistas vêm sendo

\footnotetext{
${ }_{3}^{3}$ Só a Editora Abril publica por mês mais de uma dúzia de revistas voltadas para o público feminino, tratando fundamentalmente de assuntos como moda, dietas, tratamentos estéticos e exercícios físicos. Ver: http://www.abril.com.br/revistas/

${ }^{4}$ A este respeito, ver o artigo "Mercado brasileiro de revistas em alta" (Marques, 2008). Disponível em: http://www.abi.org.br/primeira pagina.asp?id=2649.
} 
comercializadas com estas "fórmulas" há mais de um séculos, que seu público consumidor é quase absolutamente feminino e que suas vendas continuam interessantes para o mercado editorial, podemos deduzir que a beleza física é um assunto que se encontra entre as principais preocupações femininas e que está fortemente associado à construção de uma "identidade de mulher". Como afirma Naomi Wolf (1992, p. 92), as revistas femininas "são em sua maioria escritas por mulheres para mulheres sobre temas femininos e levam a sério as preocupações das mulheres".

Com este exemplo simples do campo cultural pretendemos ilustrar como a "beleza", na forma de um aprimoramento corporal constante, está constituída contemporaneamente como um aspecto central da construção dos selves femininos, e aponto como estas revistas reproduzem tal centralidade. Orientadas por um feedback constante, refletem a mesmo tempo as demandas de suas leitoras e a difusão de padrões tradicionais de femininidade que influenciam na construção de uma "identidade de mulher" hegemônica. 0 que vale ressaltar aqui é que a troca constante de informações com as leitoras serve de indicador para 0 fato de que, em alguma medida, estes padrões são demandados por elas mesmas.

0 corpo está diretamente associado à construção das identidades sociais (inclusive as de gênero) posto que, em larga medida, estas identidades se fundam nas marcas corporais, as quais podem, por exemplo, definir quem é "negro", "índio", "pardo", "velho(a)", "jovem", etc. Exemplos como este das revistas demonstram que, no caso das mulheres, a relação entre corpo e construção da identidade é ainda mais intensa, uma vez que as mesmas apresentam preocupação em constantemente "aprimorar" este corpo. Será que quanto mais perfeito é o corpo, mais "mulher" se consegue ser? Ou será que é esse processo de aprimoramento corporal ad eternum em si que expressa melhor a femininidade?

A partir do vislumbre deste constante processo de aprimoramento, podemos afirmar que o corpo feminino apresenta maior plasticidade que o corpo masculino, o que nos serve mais uma vez de indicador da beleza como aspecto central da "identidade de mulher". As "modas corporais" são bom exemplo disso, posto que atingem muito mais fortemente as mulheres do que os homens. Essa

\footnotetext{
${ }^{5}$ A mais antiga de todas é a americana Harper's Bazaar, de 1867. No Brasil, a revista Cláudia nasce em 1961. A este respeito, ver a resenha de Joana Vieira Borges (2006) "A grande dama do feminismo no Brasil", publicada na revista Estudos Feministas. Disponível em: < http://www. scielo.br/pdf/ref/v14n2/a17v14n2.pdf >
} 
plasticidade é notável nos temas "magreza" e "tamanho dos seios". Estes últimos, talvez a parte corporal feminina mais carregada de conteúdo simbólico, é também a mais suscetível às alterações ditadas pela padronização estética hegemônica contemporânea. Segundo José Tariki, presidente da Sociedade Brasileira de Cirurgia Plástica, na década de 1990, 90\% das plásticas nos seios eram feitas no intuito de reduzi-los. No ano 2000 assistimos a uma virada completa nestas estatísticas graças ao "boom do silicone" e, segundo a SBCP, no ano de 2008 a operação nos seios foi líder no ranking das plásticas, representando 33\% do total de cirurgias estéticas executadas; ou seja, de 629 mil plásticas, 151mil foram de mamas. Além disso, estima-se que as mulheres representem $88 \%$ da clientela que se utiliza deste serviço médico ${ }^{6}, 0$ que reforça nossa ideia de que 0 aprimoramento corporal constante é um traço forte da femininidade.

Uma leitura descuidada ou partidária dos números apontados pelos dois exemplos pode nos levar a crer que eles são resultado de uma estrutura dominadora, autônoma e independente, que "age" sobre as mulheres, o que já foi abordado por vários teóricos, como Pierre Bourdieu em $A$ dominação masculina (2007), Naomi Wolf em 0 mito da beleza (1992) ou Germaine Greer em The Female Eunuch (1970). Estes autores (entre outros), ao discutir a atuação dos padrões estéticos na vida das mulheres, atribuíram muito ou todo poder à referida estrutura. Mas, enquanto esta estrutura "age", o que é feito da agência dessas mulheres? A partir deste questionamento, apresentamos a lacuna teórica acerca da capacidade de agência das mesmas neste processo, entendendo que tal discussão, além de enriquecer o debate sobre a relação entre agência e estrutura, problematizará algumas conclusões das teorias feministas, principalmente as da segunda onda. Da mesma forma, serão problematizados alguns pontos de vista das teorias pós-feministas que tendem a superestimar o grau de capacidade de agência feminina e subestimar a estrutura.

No mundo profissional também podemos observar as consequências práticas que a centralidade do corpo feminino implica. Na esfera profissional feminina - para além das modelos, dançarinas, esportistas e artistas, que vivenciam esta preocupação de modo muito enfático diariamente, pois seus corpos são centrais na execução de seus trabalhos -, ressaltamos que, mesmo em ocupações em que o corpo não desempenha papel fundamental, por vezes se exige

\footnotetext{
${ }^{6}$ Todos estes números podem ser encontrados no site da SBCP. Disponível em: http://www.cirurgiaplastica.org.br/publico/ultimas10.cfm
} 
das profissionais um nível de atenção a seus corpos muito mais elevado do que elas estariam em princípio dispostas a dar.

Das comissárias de bordo, por exemplo, é exigido que apresentem "peso proporcional à altura" sob pena de, no mínimo, receber uma reclamação dos superiores ou, mais dramaticamente, perder o emprego; como aconteceu na Indian Airlines ${ }^{7}$ no começo de 2009, quando uma delas foi proibida de voar, depois de 25 anos de trabalho na companhia, por encontrar-se $2 \mathrm{~kg}$ acima do limite calculado para ela. Evidentemente, os dois quilos a mais da comissária de bordo não implicavam risco à segurança dos vôos, mas representavam uma ameaça à imagem mítica da comissária de bordo bela que a companhia pretendia manter. Não existem casos desta ordem com os comissários de bordo homens, donde depreendemos (mais uma vez) que a centralidade do corpo feminino é factual, podendo ser às vezes muito problemática.

Segundo Ana Lúcia Castro (2001, p. 75), independentemente da ocupação, "cuidar da aparência gera muitos dividendos, simbólicos e materiais, na medida em que um corpo bem cuidado pode garantir melhor performance e aceitação social". Essa perspectiva pode ser vista, por exemplo, quando se exige "boa aparência" numa entrevista de emprego. Esse código da "boa aparência", embora bastante arbitrário, faz com que em uma entrevista de emprego, a maioria das candidatas se preocupe em estar de acordo com um padrão estético estabelecido. A "boa aparência" é decodificada por elas através de determinada vestimenta, maquiagem, penteado, etc., que, segundo esta mesma compreensão do código, são entendidos como mais adequados às mulheres em contexto dessa natureza.

A antropóloga Mirian Goldenberg, em seu estudo "Mudanças nos papéis de gênero, sexualidade e conjugalidade: um estudo antropológico sobre o masculino e o feminino nas camadas médias urbanas", trabalhou com as experiências cotidianas sobre o corpo e a beleza na vida das mulheres. Utilizandose de 1.279 questionários, Goldenberg perguntou às mulheres "o que você mais inveja em uma mulher?", obtendo como resultado, em primeiro lugar a beleza, seguida pelo corpo e em terceiro, a inteligência (GOLDENBERG, 2002, p.88).

Quanto aos homens, ao lhes foram perguntados sobre o que mais lhes causava inveja nos outros homens, a resposta obtida foi: inteligência, poder econômico, beleza e corpo. Estes dados revelam claramente que na nossa sociedade

${ }^{7}$ Ver Jornal Correio do Brasil, de 01/06/2007, "Justiça indiana impede aeromoças acima do peso de voarem”. Disponível em: <http://www.correiodobrasil.com.br/noticia.asp?c=120109> 
há uma atribuição de valor à beleza física feminina que não parte apenas dos homens, mas que é também reproduzida pelas mulheres, e que, enquanto no meio social "cabe" aos homens serem inteligentes e ricos em primeiro lugar, às mulheres cabe serem belas. Como, então, as mulheres lidam com expectativas como esta? A pesquisa de Goldenberg (2002) traz a beleza como um valor feminino central para as próprias mulheres, denotando sua importância na formação destes selves.

Como mencionamos anteriormente, autores como Germaine Greer (1970), Naomi Wolf (1991), Pierre Bourdieu (1999), entre outros, nos explicariam este resultado ressaltando a sujeição do corpo feminino, e, utilizando-se do argumento de que esse corpo é socialmente controlado pela cultura androcêntrica, chegariam à conclusão de que ele é alienado de suas "donas". Para estes teóricos, há uma constante violência simbólicas atuando sobre as mulheres, as quais sofrem mitigação de autonomiae, portanto, de agência. Fatos como o aumento nos índices de transtornos alimentares, motivados por um padrão de magreza hegemônico; aumento nos índices de cirurgias plásticas meramente estéticas; saltos altos e saias, que impedem a livre movimentação corporal; e até mesmo brinquedos, que representam o que é bom (ou o que é o bem) por meio da associação com o que é belo; são também indicadores de que, em alguma medida, existe uma dimensão de violência simbólica no cotidiano feminino. Mas até que ponto pode-se afirmar que seguir determinados padrões estéticos significa abdicar da reflexividade ou mitigar a própria autonomia, como é sugerido por este conceito de violência simbólica? Será que as mulheres estão numa simples condição de vítimas? Do ponto de vista sociológico, faz sentido retirar das mulheres os seus poderes de agência nestes processos?

\section{Algumas teOrias SOBRE OS CORPOS DAS MUlHeres:}

No intuito de ilustrar o problema da agência feminina no que diz respeito aos seus próprios corpos, traçamos um rápido panorama cronológico de algumas teorias feministas que abordaram o tema "corpos de mulheres".

\footnotetext{
${ }^{8}$ Em Bourdieu, a violência simbólica ocorre quando "os dominados aplicam categorias construídas do ponto de vista dos dominantes às relações de dominação, fazendo-as assim ser vistas como naturais" (BOURDIEU, 2005, p. 46).

${ }^{9}$ Esse assunto só se legitima como objeto da teoria sociológica a partir da segunda metade do século XX.
} 
Há sessenta anos, em 1949, no clássico da literatura feminista, O Segundo Sexo, Simone de Beauvoir (1961, p. 57) escrevia que "o corpo da mulher é um dos elementos essenciais da situação que ela ocupa neste mundo. Mas não é ele tampouco que basta para a definir". Beauvoir expressou a preocupação com 0 grau de importância dado ao corpo das mulheres na hora em que se determinava a essência do "ser mulher". A autora temia que as mulheres se tornassem escravas de seus corpos devido aos processos da maternidade e, por isso, chamou a atenção para o fato de que estes corpos não são suficientes para nos definir, ressaltando que, embora elas possam ser mães, as mulheres são tão "mente" quanto qualquer homem e que processos reflexivos se dão em seus espíritos de maneira análoga a estes. Para Beauvoir, a transcendência, característica particular e devir da humanidade, só seria alcançada a partir do exercício constante da reflexividade.

Vinte anos depois, em 1970, Germaine Greer, em 0 eunuco feminino, observou que as estruturas óssea e muscular femininas eram, em larga medida, definidas pela posição social das mulheres. Visto que os trabalhos que lhes eram socialmente atribuídos exigiam um uso menos intenso dos músculos, houve uma diferenciação no desenvolvimento do corpo feminino em relação às proporções masculinas. Espartilhos e saltos, símbolos da identidade feminina, eram capazes de deformar os corpos, produzindo, por exemplo, cinturas mais finas ou nádegas mais "arrebitadas". Greer (1999, p. 41) conclui que entre homens e mulheres, várias das diferenças sexuais tidas como biológicas são, na verdade, construídas social e historicamente e que, enquanto "tratarmos os corpos de mulheres como objetos estéticos sem função, estaremos deformando eles e suas donas".

Já na década de 1990, Naomi Wolf (1992) causou polêmica afirmando que as mulheres modernas são alvos de um "mito da beleza", que se instala silenciosamente nas psiques femininas, institucionalizando a beleza física como o valor feminino mais importante. Este mito foi explicado pela autora como uma forma de controlar as mulheres, tendo sido desenvolvido por um patriarcado "ameaçado" pela crescente autonomia feminina. Seu texto não pode ser propriamente classificado como acadêmico-científico. Ainda assim, sua tese central merece atenção.

Mais recentemente, em 1999, Pierre Bourdieu (2007, p. 79), em $A$ dominação masculina conceituou o corpo das mulheres como um corpo-parao-outro: 
Tudo, na gênese do babitus feminino e nas condições sociais de sua realização, concorre para fazer da experiência feminina do corpo o limite da experiência universal do corpo-para-o-outro, incessantemente exposto à objetivação operada pelo olhar e pelo discurso dos outros.

Ao colocar desta forma, o autor atenta para a questão de que o corpo das mulheres é mais sujeito a julgamentos do que o é o corpo masculino, inclusive por parte das próprias mulheres, como vimos na pesquisa executada por Goldenberg. Nestes corpos-para-o-outro "mede-se" o nível de enquadramento nos tais padrões estéticos hegemônicos representantes da beleza feminina em determinado contexto.

Sobre estes padrões, na contemporaneidade observamos um assumido clamor pela diversidade estética, e movimentos como "Black is Beautiful" ou "Fat is Beautiful" encarnam a necessidade, com o perdão do neologismo, de uma des-hegemonização estética. Ainda assim, é notável a persistência de um padrão hegemônico, expresso na valorização da magreza (as modelos pesam, em média, 23\% menos que as mulheres comuns ${ }^{10}$ ), na insistência da pele clara ${ }^{11}$, nos cabelos forçosamente lisos (existem inúmeros cosméticos no mercado para este propósito), etc. Enfim, os valores associados à beleza feminina veiculados por estes padrões somam as influências do eurocentrismo, da indústria cultural e da "indústria da beleza"12.

Todos os autores supracitados problematizam o corpo da mulher como historicamente ocupando uma posição central na própria definição do que é ser mulher e como ele é modificado a partir desta definição, trazendo para elas várias implicações. De um modo geral, nenhuma destas teorias nos explica o que é feito do poder de agência feminino nestes processos. Ao fazer esta crítica, não pretendemos recair no erro do anacronismo e, muito menos, no da presunção acadêmica. Entendemos que todos, sem exceção, são basilares na discussão da autonomia feminina e os utilizo para alicerçar minha reflexão. Contudo,

\footnotetext{
${ }^{10}$ Ver Ana Paula Sibila (2007), "A arma de guerra chamada Barbie”. Disponível em <http://pphp. uol.com.br/tropico/html/textos/2891,1.shl>

${ }^{11}$ Consultar a contenda sobre a cota para modelos negras em eventos como a SP Fashion Week. Disponível em: <http://grupoaudienciadatv.wordpress.com/2009/05/22/lei-de-cotas-paramodelos-negras-e-polemica-entre-fashionistas/>

12 Tipologia que designa todos os setores envolvidos com a produção e/ou manutenção da beleza; indústrias de produtos de higiene pessoal, perfumaria, cosméticos, alimentos dietéticos ou "próativos", além do setor de serviços, como, academias, spas, salões de beleza, etc.
} 
enfatizamos que suas lentes teóricas estavam mais voltadas para os poderes estruturais que agem sobre as mulheres do que para os poderes transformadores ou de resistência que estas mulheres podem exercer. Por trás destes corpos, há mentes dotadas de reflexividade, capazes de processar os comentários externos. Essa dimensão reflexiva não é levada em conta no conceito bourdieusiano de habitus; todavia, é exatamente o que permite o processo de monitoramento conceituado por Margaret Archer.

Algumas teóricas pós-feministas do começo da década de 1990, como Katie Roiphe e Rene Denfeld, apontaram para o problema da recorrente vitimização das mulheres nas teorias feministas e pretendo reforçar tal apontamento neste trabalho. A própria Naomi Wolf publica, em 1993, Fire with Fire, obra na qual critica o fato de que há um descompasso entre a compreensão geral do que é feminismo e aquilo que as teóricas da área definem como tal. Para a autora, no meio social não-acadêmico, o feminismo é visto como algo tolhedor e sobrecarregado ideologicamente (ainda fortemente associado às ideias feministas da segunda onda) e isso resulta numa espécie de "êxodo" de mulheres do próprio movimento. Ou seja, para Wolf, o feminismo "tradicional" não responde mais aos anseios da mulher contemporânea e necessita de uma revisão conceitual e epistemológica.

As teorias pós-feministas exageram na capacidade da autonomia que atribuem às mulheres. Da mesma forma que as feministas de segunda onda não nos explicaram como (não) funciona o mecanismo de agência feminino, uma vez que ele é tido como mínimo ou inexistente, as "pós" também não nos trazem tal elucidação, visto que para elas o poder de agência é, de certa maneira, dado como óbvio. É exatamente em Margaret Archer, uma teórica sem nenhuma filiação feminista assumida, que conseguimos encontrar um equilíbrio plausível entre 0 alcance da agência feminina (humana) e a força exercida pela estrutura. Esse equilíbrio provém da capacidade reflexiva das pessoas.

\section{A TEORIA DA REFLEXIVIDADE}

Archer problematiza a questão da agência sob a ótica do Realismo Crítico, e, mesmo não sendo uma teórica feminista, sua teoria é muito fértil para 0 debate no campo da Sociologia. Sobre o problema da agência, considera que os indivíduos "têm poderes de monitoramento contínuo, tanto do self, quanto da sociedade" (ARCHER, 2000, p. 74). Assim, atribui-se aos indivíduos a capacidade 
de "vigiarem" tanto as suas próprias ações, quanto as "ações" do meio social. 0 sujeito nem é o centro do mundo, pleno em sua autonomia, como queriam os iluministas, nem é o fantoche da grande estrutura que é a sociedade, como poderiam entender os durkheimianos ortodoxos.

Para o esclarecimento desta noção de self, a autora nos diz que "o self é definido como o corpo mais a [...] continuidade de consciência..." (ARCHER, 2000, p. 61). Essa continuidade de consciência diz respeito à nossa capacidade de nos entendermos como um e o mesmo ser durante toda a vida, ou seja, nos particulariza em relação aos outros, permitindo a emergência de um ser único, com uma combinação única de preocupações. Além disso, o sentido de self "emerge de nossas práticas expressas na realidade e, assim, é irredutível à nossa socialidade" (ARCHER, 2000, p. 58). Isso significa que sua constituição se dá através das particulares vivências práticas do mundo, mas que, ainda assim, existe um "espaço aberto" no agente, no qual a estrutura consegue agir (para a autora, o indivíduo éparcialmente formado pela socialidade).

Cada indivíduo único decide, através de um processo reflexivo - que se dá na forma de uma conversação interna constante - como lidar com as implicações da realidade dessa vivência, seja no que diz respeito à relação com ele mesmo, seja no que diz respeito à relação com os outros. Para Archer, aquilo que assumimos como compromissos ou preocupações de alta importância sempre estará sujeito à modificação ou renovações, as quais são embasadas neste diálogo interior. A identidade pessoal surge então, consequentemente, quando um self particular torna-se capaz de decidir especificamente quais compromissos ou preocupações deverão ser realmente considerados importantes. As escolhas particulares feitas a partir deste processo reflexivo são chamadas pela autora de preocupações últimas, ou, em outras palavras, aquilo com o que mais nos importamos no mundo. Como as emoções que sentimos são "comentários" sobre essas preocupações, "a emotividade é nossa resposta reflexiva ao mundo" (ARCHER, 2000, p.64).

Para a autora, a realidade é divida em 3 ordens: natural, prática e social. Necessariamente, todos os sujeitos são impelidos a criar para si o modo de vida mais adequado para 0 gerenciamento destas três ordens, as quais por vezes demandam emoções contraditórias ${ }^{13}$. A cada uma delas corresponde um

13 "Por exemplo, uma resposta evasiva aos sinais de medo físico pode comprometer a autoestima ao produzir atos de covardia" (ARCHER, 2000, p. 65). 
tipo específico de preocupação, quais sejam, respectivamente, bem estar físico, competência performativa e autoestima. Para os objetivos deste trabalho, a última preocupação merece destaque, muito embora o cuidado com a aparência também possa ser justificado através da busca pela saúde ou por aceitação social. Segundo Archer, a autoestima do sujeito é definida por ele próprio. Como ela escreve, "são as nossas próprias definições do que constitui autoestima que determinam que avaliações normativas são importantes o suficiente para que sejamos emotivos acerca delas" (ARCHER, 2000, p. 65).

Essa ideia archeana, relativamente simples, abre-nos para uma discussão sobre a relação entre agência e estrutura bastante refinada, posto que, se a autoestima se calca nos nossos próprios valores, o processo de construção da autoestima passa a ser um tanto mais "interno" do que parece a principio; ou seja, as influências externas deixam de fazer sentido per se.

Logo, os padrões estéticos hegemônicos, tão abominados pelo movimento feminista da segunda onda, perdem boa parte de seu poder, uma vez que, segundo a teoria archeana, só serão por nós reconhecidos como algo que deve (ou não) ser seguido mediante um processo reflexivo de monitoração que define nossas preocupações últimas. A autora nos dá a possibilidade de pensar que, ao seguirem estes padrões, as mulheres não estão necessariamente abdicando de suas dimensões reflexivas, mas sim que ativamente decidem o que deve ou não ser levado em consideração.

Como ressaltamos acima, se somos parcialmente formados por nossa socialidade, de alguma forma estes padrões influenciam na construção de nossas identidades. 0 que o argumento de Archer nos permite vislumbrar é que cada mulher tem a possibilidade de escolher (embora isso não seja necessário) como e em que medida estes padrões serão levados em consideração. Essa possibilidade de devolução do poder de agência feminino questiona alguns pressupostos das teorias feministas mais tradicionais e responde a anseios como o colocado por Wolf em Fire with Fire, mostrando-nos que as mulheres "podem ser" sujeitos ativos, e não meras receptoras da influência externa. A riqueza do pensamento archeano está neste "poder ser", posto que a autora afirma que, mesmo que a reflexividade seja "a" propriedade eminentemente humana, as pessoas só serão especialmente ativas na medida em que assim se decidirem.

A partir daí, podemos compreender que, embora as mulheres: 1) sejam fortemente associadas à natureza, haja vista a centralidade conferida às suas 
capacidades corporais reprodutivas e de maternagem e 2) sejam socializadas de forma que seus corpos figuram como um elemento definidor de suas identidades; suas capacidades reflexivas e suas definições particulares de autoestima as levam a assumir ou não qualquer um destes supostos valores femininos. Ou ainda, se lhes aprouver, transformá-los e vivenciá-los de acordo com suas expectativas ou necessidades pessoais.

Bourdieu (2007) acredita que processos de naturalização de valores (como estes) se devem a um trabalho histórico incessante, posto que nenhum fato social é "natural" per se, e todos os construtos da sociedade são culturalmente erigidos. Esta noção de sentido bistoricamente construído nos ajuda a aclarar tanto a centralidade do corpo quanto a associação entre beleza e feminilidade na formação das mulheres.

Comportamentos corporais incorporados são explicados por Marcel Mauss através de uma motivação que vai além da mera educação, baseada no fato de que, socialmente, "vale a pena" imitar indivíduos de prestígio. Se uma determinada pessoa reconhecidamente prestigiada apresenta-se de determinada maneira e, por isso, é socialmente aprovada, logo ela legitima tal postura, dando margens à imitação (mesmo que este futuramente imitado não esteja cônscio desta sua "influência"). Para o autor, é "precisamente nessa noção de prestígio da pessoa que faz o ato ordenado, autorizado, provado, em relação ao indivíduo imitador, que se verifica todo o elemento social" (MAUSS, 2003, p. 405).

Este conceito maussiano nos permite compreender como se formam os padrões estéticos hegemônicos, ou como se fundam os padrões de beleza. Ou seja, de forma geral, um padrão estético se constitui a partir de uma cadeia de eventos que ocorrem graças a uma legitimação dos pares, a qual gera uma subsequente imitação que pode extrapolar ou não o universo desses pares. Na contemporaneidade os meios de comunicação (principalmente as revistas femininas) e a publicidade ${ }^{14}$ exercem um forte papel na propagação de tais padrões. Um exemplo desta cadeia de imitação pode ser visto acima, na fala do Dr. Tariki, que nos mostra como, em pouco tempo, um padrão corporal, no caso, o tamanho dos seios, (algo que para ser modificado exige um alto investimento monetário e psicológico para ser mudado) se alterou de um extremo para outro. Não existe outra explicação para

\footnotetext{
${ }^{14}$ Segundo Ana Jorge, as revistas têm "uma forte componente de aconselhamento, afirmaram-se junto dos leitores como 'amigas', 'confidentes', 'companheiras', transferindo a sua credibilidade para a publicidade" (JORGE, 2008, p. 25).
} 
este fenômeno da multiplicação do silicone a não ser esta "ordem" legitimaç̧ãoimitação, uma vez que per se, o silicone não representaria nenhum benefício às mulheres que 0 utilizam.

Todavia, intentamos sustentar que até mesmo na imitação existe uma dimensão reflexiva, uma vez que a pessoa que imita não imita qualquer um, escolhendo ela mesma, quem ou o quê "é digno" de ser imitado, monitorando e/ou interrompendo tal processo mediante determinadas condições específicas. Nessa moda do silicone, por exemplo, nem todas as mulheres sentiram-se interessadas em alterar o tamanho de seu próprio busto. A capacidade reflexiva permite ponderação e escolha, inclusive uma escolha por imitar algo.

As "modas" se apresentam como um indicador desta "lógica imitativa", pois o processo de imitação via moda permite tanto diferenciar-se de que quem não se admira, quanto aproximar-se de quem se admira. Os adolescentes, que, para Archer, ainda não têm claras suas preocupações últimas, posto que suas identidades pessoais ainda estão em formação, vivenciam estas variações com muita intensidade. Para a autora, "nos associamos a, e celebramos com, aqueles que compartilham nossos compromissos, e 'desconforto' é o sentimento transvalorizado que nos separa daqueles com compromissos contrários" (ARCHER, 2000, p. 67).

Apoiando-nos em Archer, ressaltamos que, mesmo que o "imitar" possa ser considerado um ato não-reflexivo (segue um parâmetro pré-dado), o imitador tem, a todo momento, tanto a possibilidade de criar algo novo como de desvincularse daquela imitação que a princípio pode ter sido por ele considerada um compromisso válido. Ao relacionar a teoria de Marcel Mauss à teoria de Margaret Archer, pretendemos mostrar que ainda que a reflexividade seja uma propriedade humana fundamental responsável por uma gama de poderes causais, ela não necessariamente conduz os sujeitos à autonomia nem aumenta suas capacidades de agenciamento. A reflexividade simplesmente possibilita que o ser humano monitore tanto as suas próprias ações como as impressões que ele recebe do meio. De fato, a conquista de uma suposta autonomia e o incremento da capacidade de agenciamento passam necessariamente pela reflexividade; mas, tais metas só serão efetivadas na medida em que o próprio sujeito designá-las como objetivos a serem perseguidos, ou, na terminologia archeana, como preocupações últimas.

A relação entre mulheres e beleza parece bastante mais razoável e dotada de sentido se observada através dessa possibilidade sociológica, uma vez que numa 
mesma sociedade temos a chance de observar mulheres que cultuam fortemente a preocupação estética e outras para quem isto aparece esporadicamente e ainda há aquelas que jamais pensam no assunto. Estes posicionamentos não são estanques, sendo passíveis de variação a todo momento. Se não for justificado idiossincraticamente, ou seja, se queremos uma explicação sociológica para tal fato, é preciso atentar que essa riqueza de posturas diante de um valor social hegemônico se torna acachapada na medida em que não levamos em consideração o dinamismo do processo reflexivo, sua constante capacidade de monitoramento e de subsequente poder causal. Um tal deslize sociológico empobrece a própria discussão teórica. Neste sentido, a contribuição de Archer acerca do problema sobre a relação entre agência e estrutura pode ser entendida como uma das mais relevantes na contemporaneidade.

\section{REFERÊNCIAS}

ARCHER, Margaret: Realismo e o poder da agência. Estudos de Sociologia, Araraquara, vol. 6, n. 2, p. 51-75, jul/dez, 2000.

. Structure, agency and the internal conversation. Cambridge: Cambridge University Press, 2003 Press, 2000.

. Being buman: The problem of agency. Cambridge: Cambridge University

BEAUVOIR, Simone. O segundo sexo. São Paulo: Difusão Européia do Livro, 1961. BORGES, Joana Vieira Borges. A grande dama do feminismo no Brasil. Estudos Feministas, Florianópolis, vol. 14, n. 2, p.553-555, mai/ago, 2006. Disponível em: $<$ http://www.scielo.br/pdf/ref/v14n2/a17v14n2.pdf>

BOURDIEU, Pierre. A dominação masculina. Rio de Janeiro: Bertrand Brasil, 2007.

CASTR0, Ana Lúcia. Culto ao corpo e sociedade: mídia, estilos de vida e cultura de consumo. São Paulo: Annablume: Fapesp, 2007.

DOMINGUES, José Maurício. Teorias sociológicas no século XX. Rio de Janeiro: Civilização Brasileira, 2004.

GAMBLE, Sarah. The icon critical dictionary of feminism and postfeminism. Cambridge: Icon Books Ltd., 1999. 
GREER, Germaine. The female eunuch. Londres: Flamingo, 1999.

GOLDENBERG, Mirian. A construção social do corpo: um novo modelo de ser mulher. Revista da FACED, Salvador, n. 6, Salvador, 2002. Disponível em: <http:// www.portalseer.ufba.br/index.php/rfaced/article/view/2777/1955>.

JORGE, Ana. Revistas com estilo. Jornalismo e jornalistas, Lisboa, n.35, jul/set. 2008. Disponível em: <http://www.clubedejornalistas.pt/uploads/ji35/ji35_24. pdf $>$. Acesso em 16/11/2009

JORNAL CORREIO DO BRASIL. Justiça indiana impede aeromoças acima do peso de voarem. 01/06/2007. Disponível em: <http://www.correiodobrasil.com.br/ noticia.asp?c $=120109>$

MARQUES, José Reinaldo. Mercado brasileiro de revistas em alta.ABI - Associação Brasileira de Imprensa, Rio de Janeiro, 01 de Agosto de 2008. Disponível em $<$ http://www.abi.org.br/primeira pagina.asp?id=2649>. Acesso em 15/11/2009.

MAUSS, Marcel. Sociologia e antropologia. São Paulo: Cosacnaify, 2003.

ORTNER, Sherry. Está a mulher para o homem assim como a natureza para a cultura? In: ZAMBALIST, Michele e LAMPHERE, Louise (orgs.). A mulher, a cultura e a sociedade. Rio de Janeiro: Paz e Terra, 1979.

SAYER, Andrew. Características chave do realismo crítico na prática: um breve resumo. Estudos de Sociologia, Araraquara, vol. 6, n. 2, p. 7-32, jul/dez de 2000.

SIBILA, Ana Paula Sibila. A arma de guerra chamada Barbie. Trópico, 27/07/2007. Disponível em http://pphp.uol.com.br/tropico/html/textos/2891,1.shl

WOLF, Naomi. 0 mito da beleza: como as imagens de beleza são usadas contra as mulheres? Rio de Janeiro: Rocco, 1992. 